\title{
BMJ Open Defining acute flares in knee osteoarthritis: a systematic review
}

To cite: Parry EL, Thomas MJ, Peat G. Defining acute flares in knee osteoarthritis: a systematic review. BMJ Open 2018;8:e019804. doi:10.1136/ bmjopen-2017-019804

- Prepublication history and additional material for this paper are available online. To view these files, please visit the journal online (http://dx.doi. org/10.1136/bmjopen-2017019804).

Received 27 September 2017 Revised 10 April 2018 Accepted 15 May 2018
Check for updates

(C) Author(s) (or their employer(s)) 2018. Re-use permitted under CC BY-NC. No commercial re-use. See rights and permissions. Published by BMJ.

Arthritis Research UK Primary Care Centre, Research Institute for Primary Care \& Health Sciences, Keele University, Keele, Staffordshire, UK

Correspondence to Professor George Peat; g.m.peat@keele.ac.uk

\section{ABSTRACT \\ Objective To identify and critically synthesise definitions of acute flares in knee osteoarthritis $(\mathrm{OA})$ reported in the medical literature.}

Design Systematic review and narrative synthesis. We searched Medline, EMBASE, Web of science and six other electronic databases (inception to July 2017) for original articles and conference abstracts reporting a definition of acute flare (or synonym) in humans with knee OA. There were no restrictions by language or study design (apart from iatrogenic-induced flare-ups, eg, injection-induced). Data extraction comprised: definition, pain scale used, flare duration or withdrawal period, associated symptoms, definition rationale, terminology (eg, exacerbation or flare), baseline $0 A$ severity, age, gender, sample size and study design.

Results Sixty-nine articles were included (46 flare design trials, 17 observational studies, 6 other designs; sample sizes: 15-6085). Domains used to define flares included: worsening of signs and symptoms (61 studies, 27 different measurement tools), specifically increased pain intensity; minimum pain threshold at baseline (44 studies); minimum duration (7 studies, range 8-48 hours); speed of onset (2 studies, defined as 'sudden' or 'quick'); requirement for increased medication (2 studies). No definitions included activity interference.

Conclusions The concept of $\mathrm{OA}$ flare appears in the medical literature but most often in the context of flare design trials (pain increases observed after stopping usual treatment). Key domains, used to define acute events in other chronic conditions, appear relevant to $0 \mathrm{~A}$ flare and could provide the basis for consensus on a single, agreed definition of 'naturally occurring' OA flares for research and clinical application.

PROSPERO registration number CRD42014010169.

\section{INTRODUCTION}

Recurrent acute events or episodes feature in the natural history of many chronic health conditions. The extent to which they characterise the condition varies, as do the presumed pathophysiological mechanisms, and scientific and lay terms used to describe them (eg, an acute exacerbation of chronic obstructive pulmonary disease (COPD) or asthma, an attack of gout or a rheumatoid arthritis flare). With recognition of their importance has come concerted effort to define these phenomena. Definitions for exacerbations or flares currently exist for COPD, ${ }^{12}$ asthma, ${ }^{3}$
Strengths and limitations of this study

- Identified key domains that are used to define acute events by undertaking a comprehensive synthesis of definitions used in the medical literature.

- Broad search strategy covering a wide range of databases including bibliography checks and conference abstracts.

- Prospectively registered with an international register of systematic reviews (PROSPER0).

- Did not include potential synonyms as search terms ('attack', 'episode', 'fluctuations').

- Data extraction was performed by only a single reviewer.

systemic lupus erythematosus $(\mathrm{SLE})^{4}$ and ankylosing spondylitis $(\mathrm{AS})^{5}$ and there are working groups currently trying to define these for rheumatoid arthritis, ${ }^{6-8}$ gout $^{9}$ and atopic dermatitis/eczema. ${ }^{10}$ Despite the different language used, these definitions share some common, core domains: the onset or worsening of symptoms and signs above normal day-to-day variability; speed of onset; duration of sustained worsening and change in medication/healthcare usage.

Osteoarthritis (OA) appears to comprise multiple disease trajectories ${ }^{11-15}$ and symptom variability over time and the presence of intermittent pain is well-recognised. ${ }^{16}$ Although OA does not typically have the same very obvious acute events as conditions like gout, flares in OA joints are encountered in practice, these phenomena appear in patient literature, ${ }^{17}$ have been discussed in expert reviews ${ }^{18}$ and are mentioned in 'flare design' trials in OA. ${ }^{19}$ These studies induce acute episodes of pain or flare-ups by asking patients to withdraw their usual medication.

In 2009, Marty et al proposed scoring criteria for knee OA flares based on nocturnal awakening, knee effusion, morning stiffness and limping, ${ }^{20}$ but it is unclear whether this has contributed to a common understanding, shared terminology and criteria. A common definition of OA flare could be important for a number of reasons: (i) to facilitate communication between researchers, (ii) to allow 
more direct comparisons between studies on frequencies, determinants and course of events, (iii) to facilitate new insights into novel pathophysiological mechanisms and treatments through valid and homogenous case definitions and (iv) to help clinicians with prompt diagnosis and management.

The aim of this systematic review was to explore the extent to which a concept of OA flare is reported in the medical literature and the prospects for a common, shared definition of these for research and clinical application.

\section{METHODS}

This systematic review was registered with PROSPERO registration number CRD42014010169. The review protocol has not been published.

\section{Literature sources and study selection}

We searched electronic databases from inception to July 2017; ASSIA, EMBASE, Web of Science, Health Management Information Consortium (HMIC), SPORTDiscus, Medline, CINAHL, PsycINFO, AMED, Ageline, Cochrane Database of Systematic Reviews and Cochrane Controlled Clinical Trials (CENTRAL). The search was developed using previously piloted terms for knee OA and a literature search for common terms used to describe acute events. Searches used combined and/or truncated key terms including: ('KNEE OSTEOARTHRITIS' OR (knee N3 pain) OR (knee N3 arthrosis) OR (knee N3 joint) OR (knee N3 osteoarthritis)) AND (exacerbation OR flare OR (pain AND (diary OR diaries)) OR (pain N3 variab*) OR (pain N3*) OR (pain N3*) OR (pain N3*) OR (pain N3 pattern\$) OR (daily N3 pain)). A database search strategy is included in the online supplementary table 1. Reference lists of all included full-text articles retrieved for detailed examination were manually searched.

Studies were included in the final full-text peer-review if they contained a description or definition of an acute exacerbation or flare-up of knee $\mathrm{OA}$ in human adults (aged 18 years or over) in the general population, primary care or hospital settings. Studies were included even if their description was not based on clear measurement criteria (eg, stating a 'significant increase in pain' but not the amount of change on a pain score this would equate to). Studies that included a mixed OA population (eg, knee or hip OA) and did not separately report knee-specific findings were included. There were no restrictions on study dates or design. All non-English language articles were translated to identify a flare definition. Theses, dissertations, book chapters and guidelines and animal studies were excluded. Conference abstracts were included if they contained a definition for an OA flare-up. Studies were excluded if the flare was induced by an iatrogenic source, for example, injection-induced flares, ${ }^{21}$ as these may have been caused by a different pathophysiological process. Abstracts were included in this study as the main outcome of interest was the definition of flare used and it was decided that including abstracts would ensure a more comprehensive review. For each abstract, a search was conducted to identify a corresponding full-text paper. Where one was found only the full paper was included in the review.

The search and article retrieval was conducted by the first reviewer (ELP). Articles were downloaded into RefWorks bibliography and database manager (RefWorks Copyright 2009). Duplicates were removed and all titles were screened by ELP against inclusion criteria, with the first 20 titles checked by two reviewers (ELP and MJT) for consistency. For qualitative studies, all identified potentially eligible fulltext articles were obtained.

All abstracts and then full-text articles were screened by two reviewers (ELP and MJT), with disagreements resolved by consensus adjudicated by a third reviewer (GP). Where articles could not be retrieved or if the flare definition used was not included in the text, contact with authors was made.

The final included articles were checked to ensure results were not duplicated, for example, where different authors were reporting on the same dataset, to reduce bias. ${ }^{22}$ For articles containing pooled studies, the original studies were sought and included in the main analysis, where available. No full-text articles were required to be translated.

\section{Data extraction}

The following data pertaining to flares were extracted from full-text articles by the first reviewer: definition used for change in pain, pain scale used, duration of flare (for flare design trials we extracted the duration of the withdrawal period for comparison), associated symptoms, rationale behind definition used, terminology used (eg, exacerbation or flare), baseline OA severity, age range, gender, geographical location, number of participants and study design. Missing data were described in the data extraction tables.

\section{Quality assessment of included studies}

Our aim was to identify and contrast definitions of flare-ups used in the literature. We were not concerned with the methodological rigour of the studies deriving, evaluating or applying those definitions. However, for studies presenting definitions we sought supporting statements that gave the rationale for the definition.

\section{Data analysis}

A narrative synthesis was undertaken guided by the fourstage process of Popay et al. ${ }^{22} 23$ This approach was chosen as it allowed the words and text in the definitions to be synthesised to summarise findings. ${ }^{23}$ The initial data extracted were grouped into drug withdrawal studies ('flare design') and other studies. Frequencies of components included in definitions was tabulated, these included; terminology used, onset/worsening of symptoms; signs/symptoms above day-to-day variability/ minimum threshold; speed of onset of symptoms; duration of worsening and change in medication/healthcare usage. 


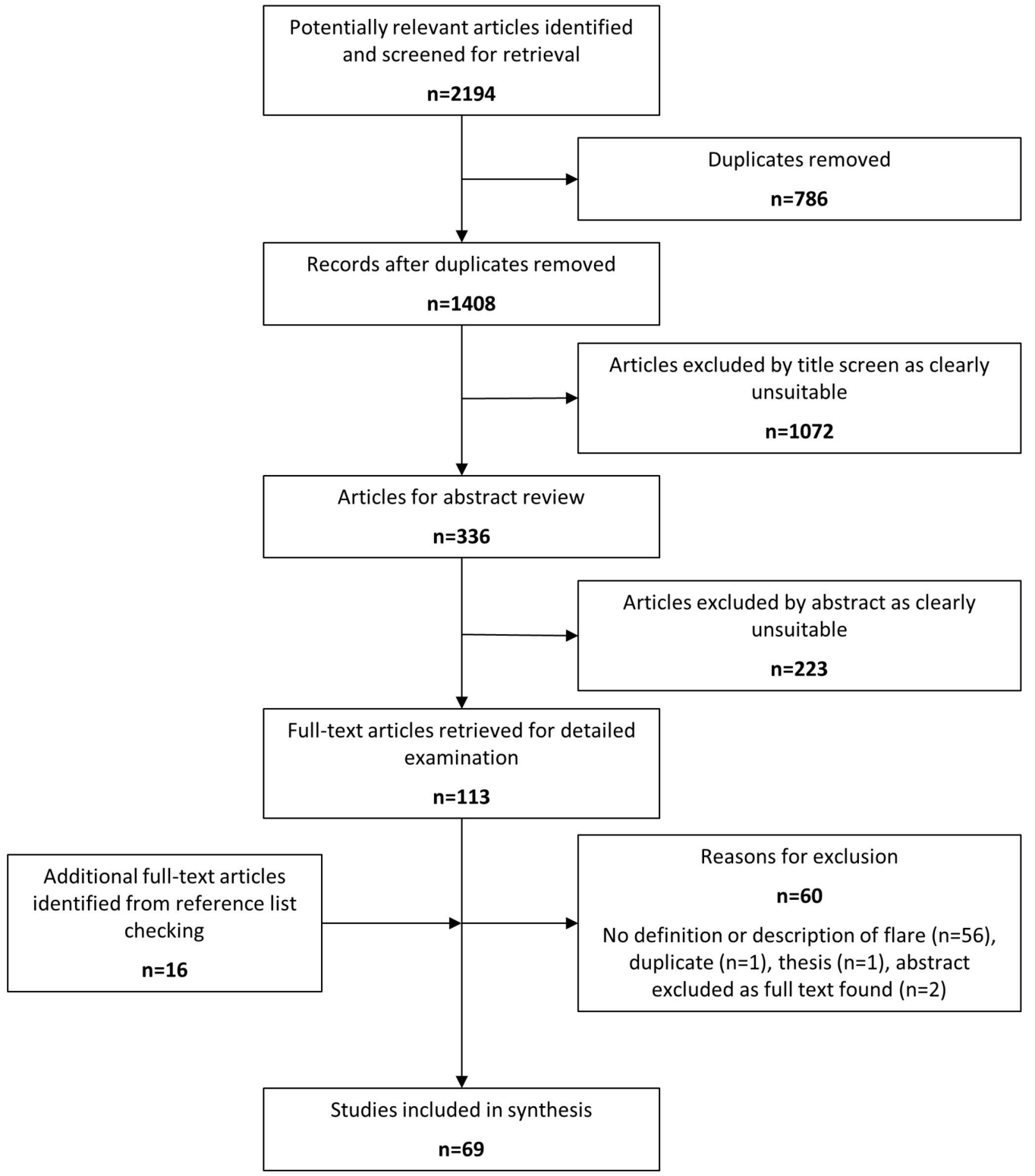

Figure 1 Preferred Reporting Items for Systematic Reviews and Meta-Analyses flow chart.

This initial tabulation helped identify similarities and differences and allowed themes to emerge. This was done with an inductive-type approach, where possible, that is, without an a priori assumption, and deductively acknowledging that the reviewers were clinicians, that is, they had some background knowledge of the topic of interest. This allowed further examination of the differences of definitions used in drug withdrawal and non-drug withdrawal study designs, and examination of key components of definitions used.

\section{Patient and public involvement}

There was no patient or public involvement in this study.

\section{RESULTS}

\section{Study selection}

The literature search yielded 2194 articles, of which 786 were duplicates (figure 1). After title screening,
336 abstracts were reviewed, 223 were not relevant for the study purpose. One hundred thirteen articles were examined in full, which resulted in a further 60 being excluded. The main reason for exclusion was no definition of flare-up reported in text $(n=56)$. At this stage, a further 16 articles were identified from the reference lists of the retrieved full-text articles resulting in 69 included studies for synthesis.

\section{Study characteristics}

Characteristics of the included studies are described in table $1 .^{2024-91}$ The number of participants in each study ranged from 15 to $6085 .{ }^{2048}$ Knee OA was defined by clinical and/or radiological criteria.

Twenty-one included mixed knee and hip OA groups. ${ }^{24} 293137-394245-47545557-596371737577$ In total, 46 publications used a drug withdrawal RCT design, ${ }^{24} \quad 26-32 \quad 34-43 \quad 45-53 \quad 55-64 \quad 73-77 \quad 88-91 \quad 4$ of which 


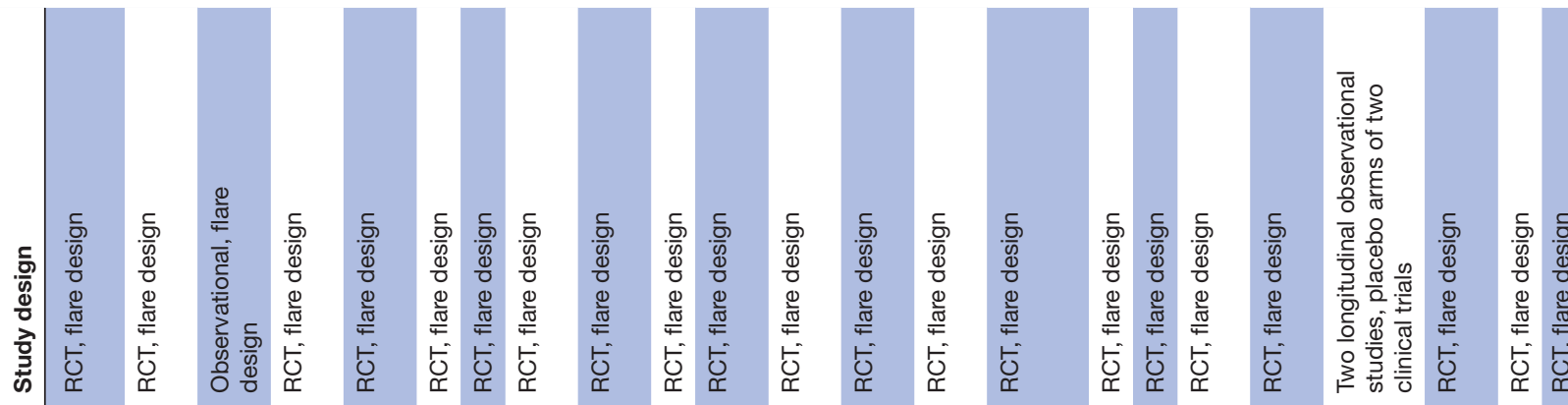

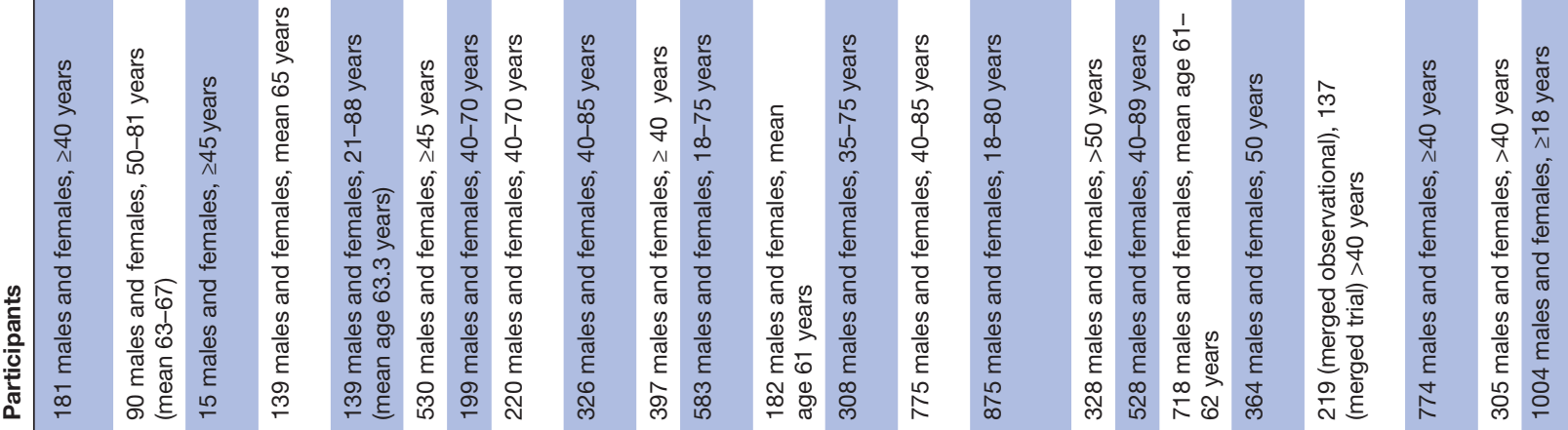
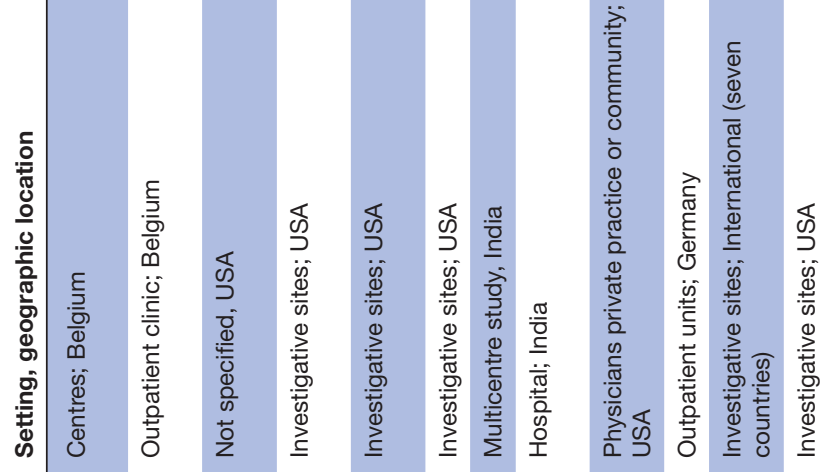

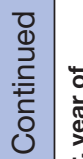
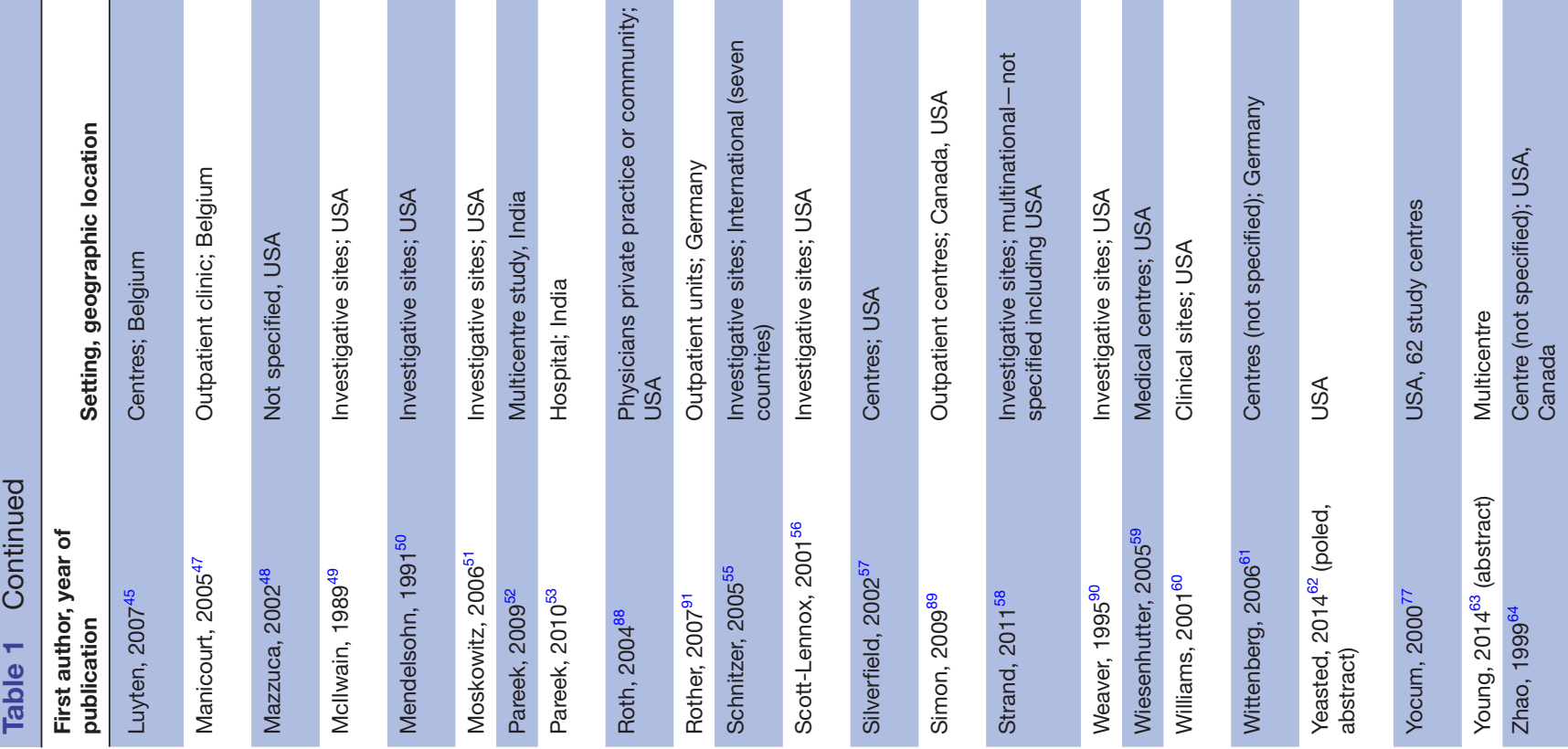


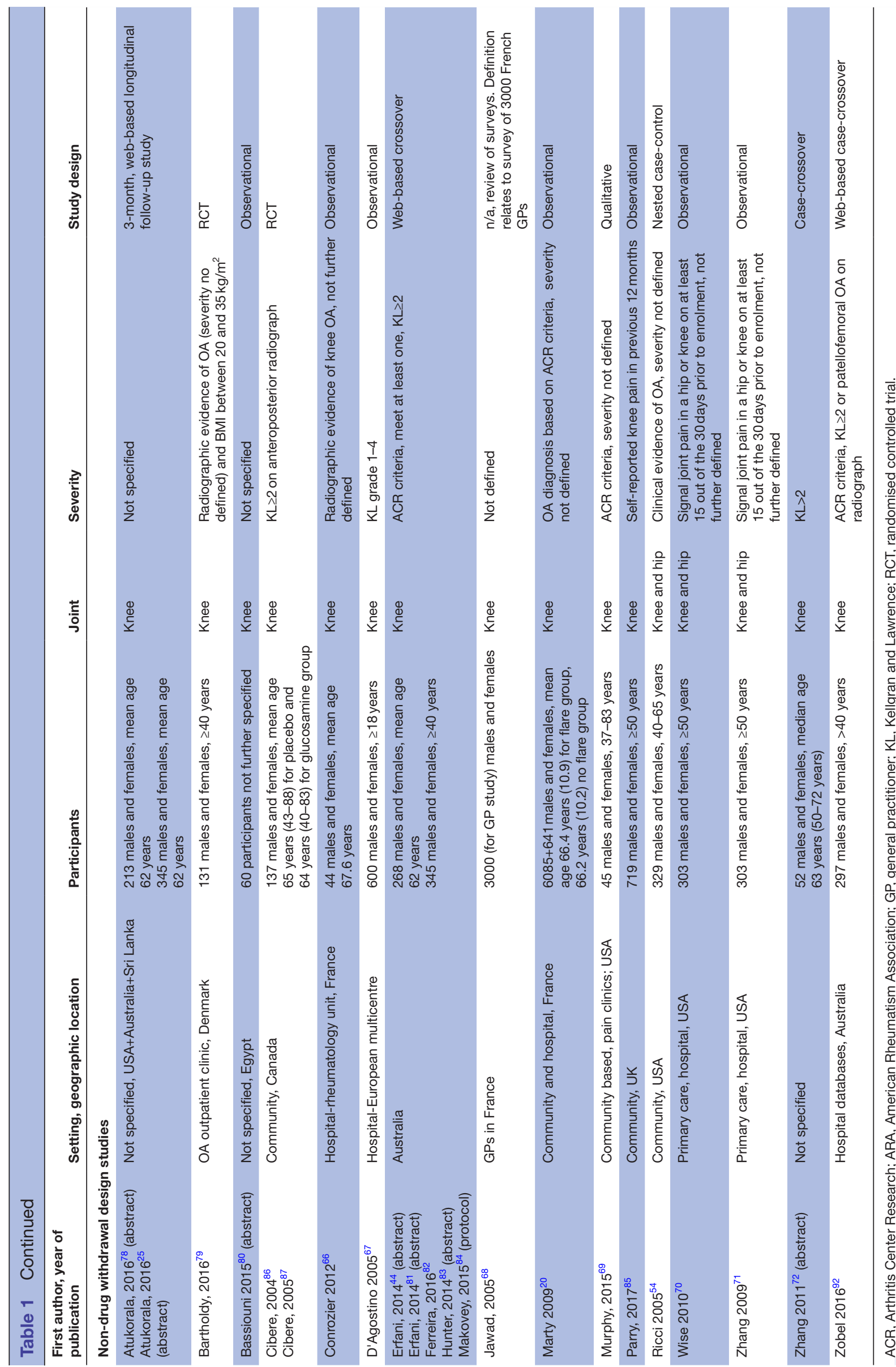

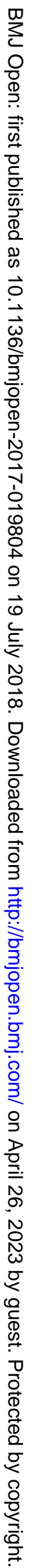


were pooled studies ${ }^{28} 324162$ and 1 used a cohort drug withdrawal design ${ }^{33}$ (table 1 ). The remaining 22 publications included 17 observational studies, ${ }^{20} 25445465-6770-727880-853$ RCTs, ${ }^{79} 86871$ survey $^{68}$ and 1 qualitative interview study. ${ }^{69}$ Nine of the included studies were abstracts. ${ }^{25} 4462637278808183$ Two abstracts were removed as the corresponding full-text article was available. ${ }^{69}{ }^{92}$ Studies using pooled data or the same dataset were included if they used different definitions of OA flare. 284452536265707174

\section{Rationale given for flare definitions}

Six of the included studies gave rationale for the definition used. ${ }^{20} 5456698586$ None of the definitions was based on a consensus procedure. The studies by Marty et $a t^{20}$ and Scott-Lennox $e t a \tilde{\nu}^{6}$ were the only ones that undertook empirical investigation of flare definitions. The study by Marty $e t a l^{20}$ was the only study specifically designed to validate a diagnostic tool for knee OA flares. Potential factors associated with flare-ups were identified, for example, knee swelling and the authors used a logistic regression analysis to assign a weight to each of the items identified. A flare-up score was determined using a general practitioner database and this was then validated using a rheumatologist database. Pain was not included in the final model.

Scott-Lennox et a $\bar{l}^{\tilde{6}}$ sought to test whether four measures for flare intensity (patient's self-assessment of pain scores, physician's assessment of pain scores, patient's global OA assessment and physician's global OA assessment) could be combined to form a reliable and valid index using data from an RCT using a confirmatory factor analysis. The authors produced three flare intensity groups (low, moderate and severe) and highlighted how these could be used to examine treatment effects.

Cibere $e t a l^{86}$ outlined face validity checks. It was specified that the flare definition had been determined by study rheumatologists to be a clinically important change in the Western Ontario and McMaster Universities Osteoarthritis Index (WOMAC) score. The definition used by Murphy et $a l^{69}$ was informed by two studies, ${ }^{28} 53$ which used a drug withdrawal design and from the research team's own experience. Ricci et a $\tilde{l}^{54}$ used a combination of data-driven and clinical judgement approaches to establish an agreed cut point. Parry et al based their definition on OA flare design studies and flare definitions used in other chronic disease such as back pain and COPD.

\section{Flare definitions in drug withdrawal studies \\ Terminology used}

The majority of publications using a drug withdrawal design used the term 'flare' in their description $^{24-30} 32$ 33 36-43 45-49 51 53 55-64 74-77 88-91 $(\mathrm{n}=42$; table 2).

One study used the term 'flare-up, ${ }^{52}$ two studies referred simply to 'worsening of symptoms ${ }^{, 3150}$ and three studies used no specific label. ${ }^{34} 3573$
Coverage of key components

Onset/worsening of symptoms and signs beyond normal-dayto-day variability: forty-four studies included onset or worsening of signs and symptoms as part of their definition. ${ }^{24}$ 26-32 34-41 43 45-53 55-64 73-75 77 88-91 All studies included increased pain intensity in their definition. A further two $^{52} 53$ specified further signs and symptoms. These included swelling, inflammation, erythema, morning stiffness and nocturnal pain. No studies quantified day-to-day variability.

Twenty-six measurement tools were used to define onset/worsening of symptoms and signs. The most commonly used tools were the Western Ontario and McMaster Universities Arthritis index (WOMAC) Q1 (pain on walking on flat surface) $100 \mathrm{~mm}$ Visual Analogue Scale (VAS) (n=9) 293032384145597375 and the Investigator Assessment of Disease Status ( $\mathrm{n}=11$ ) 28-30 $3840455973-7577$ (table 3). Thirty-four studies used only single-item measurement tools, ${ }^{27-30} 32$ 34-43 45 47 $4850525556585961-63$ 73-779091 five used multiitem $^{3146515360}$ and five used both single-item and multiitem tools. ${ }^{24} 26338889$

In addition, the format of global ratings appears to be variable as is use and reporting of the WOMAC. ${ }^{93}$ However, despite the exact format of reporting being inconsistent, in general, studies used single items in four areas-pain on activity, pain (not necessarily on activity), physician/ investigator global rating and patient global rating.

Temporal characteristics: none of the included drug withdrawal design studies reported a specific time for defining the speed of onset of symptoms. However, they did describe withdrawal or 'washout' periods, whereby after withdrawal of usual medication, participants were given a certain time frame in which to experience 'flare' symptoms in order that they were entered into the study. In total 30 of the studies specified a withdrawal period.27 $303133-3638-404345-5256586061647374767788-90$

Four studies specified a time period for minimum duration of symptoms, which ranged from 24 hours to 5 days. ${ }^{52} 535557$

Change in medication or healthcare usage: only one study used increase in medication as part of their definition; 'pain requiring supplemental analgesic medication and/ or an increase in non-steroidal anti-inflammatory drug dose'. ${ }^{57}$

Additional domains: thirty-six studies included a minimum threshold, which was usually a minimum level of pain that was required before the participant was considered to have a flare. ${ }^{24} 26$ 28-31 33 35-38 40-43 45-47 51-53 55 56 58-63 73 75 76 88-91 There was general concordance with the minimum thresholds that different measurement tools used with a few exceptions. A threshold of $40 \mathrm{~mm}$ on a $0-100 \mathrm{~mm}$ scale was used in 8 of 10 studies using the WOMAC VAS 3.0 Q1 'pain on walking on a flat surface, 2930384145597375 and 4 of 14 studies using the Patient Global Assessment of Disease Status. ${ }^{29} 457375$ In studies using various forms of Investigator/Physician Global Assessment, the majority adopted a minimum threshold for a flare of 'fair, poor 


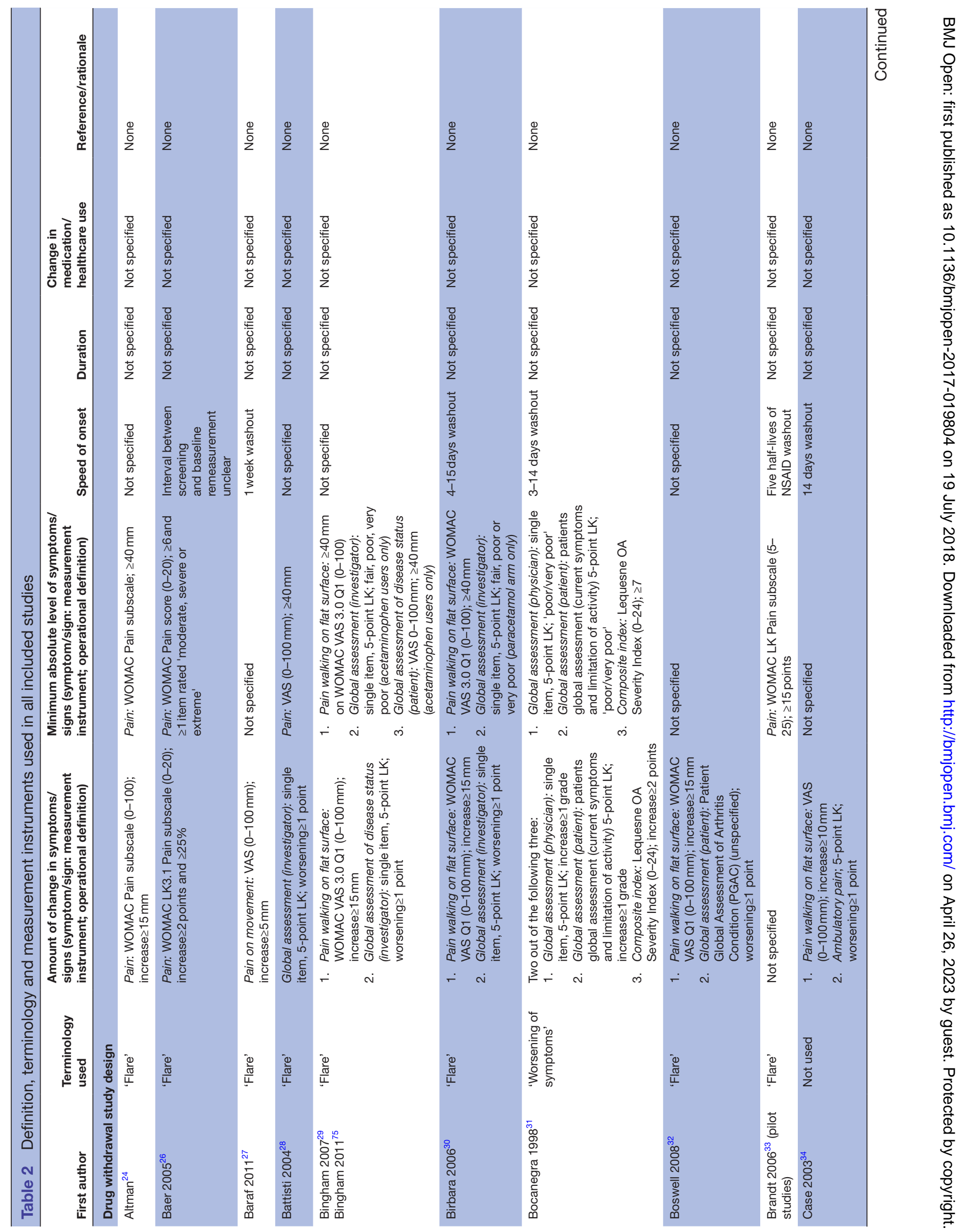




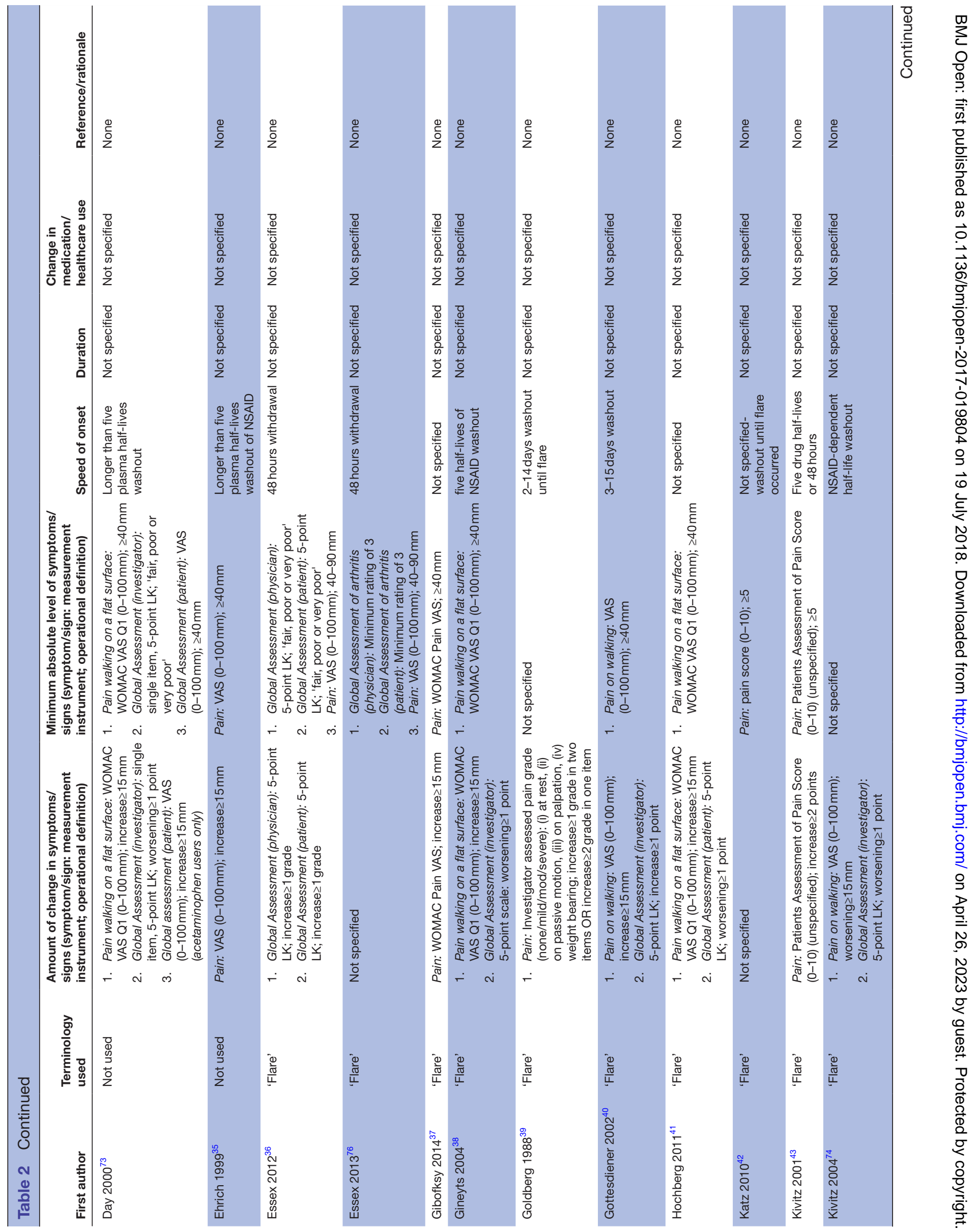




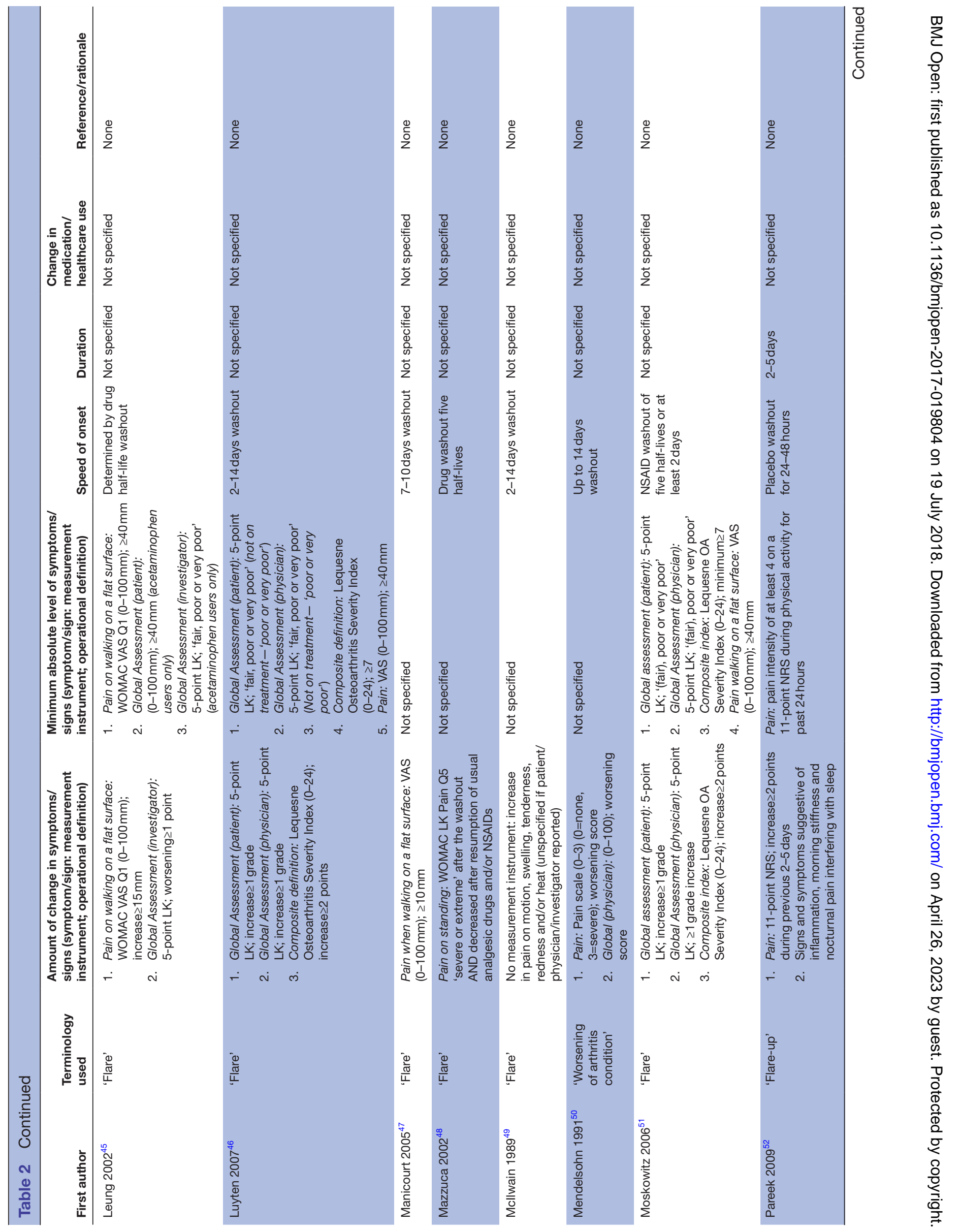




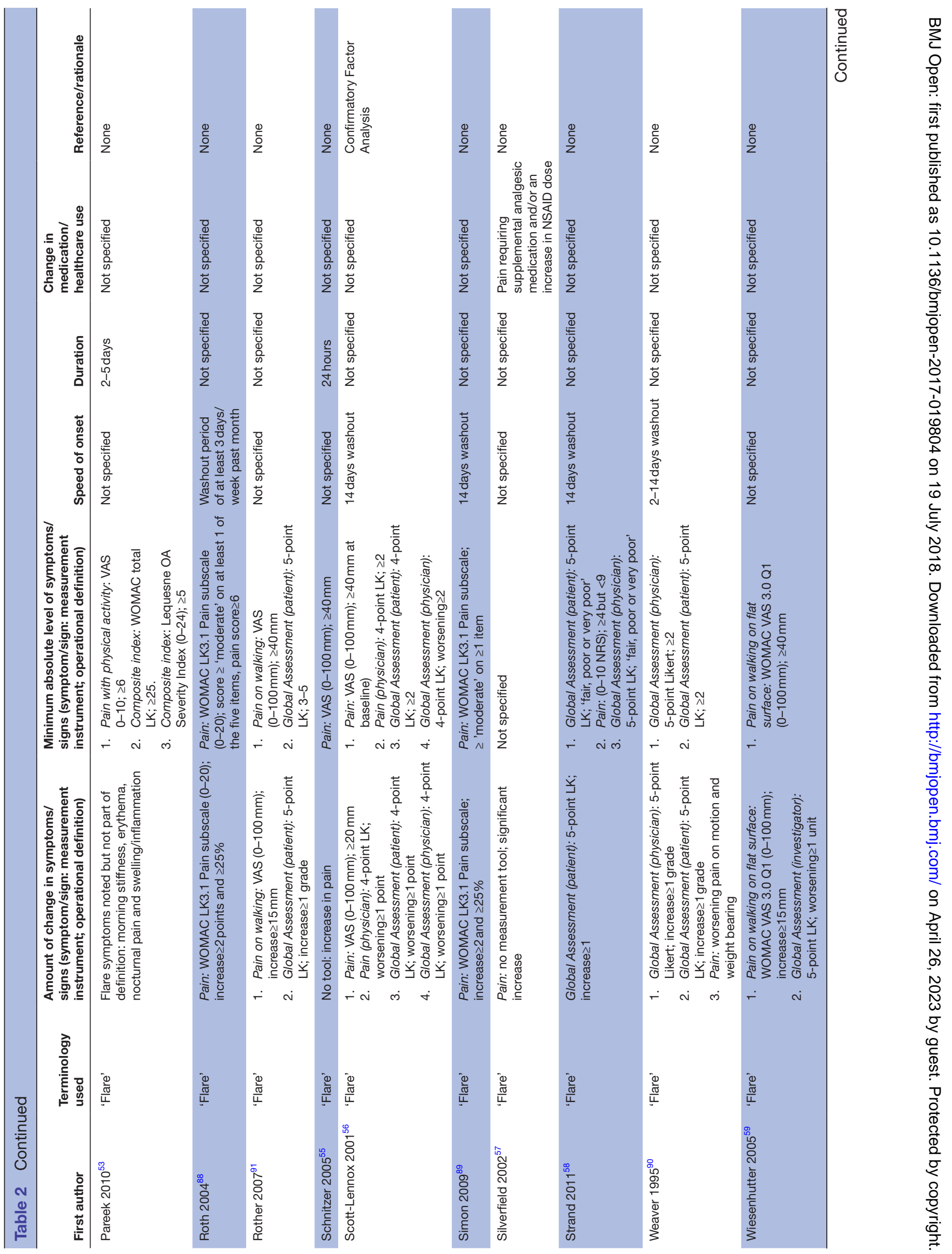




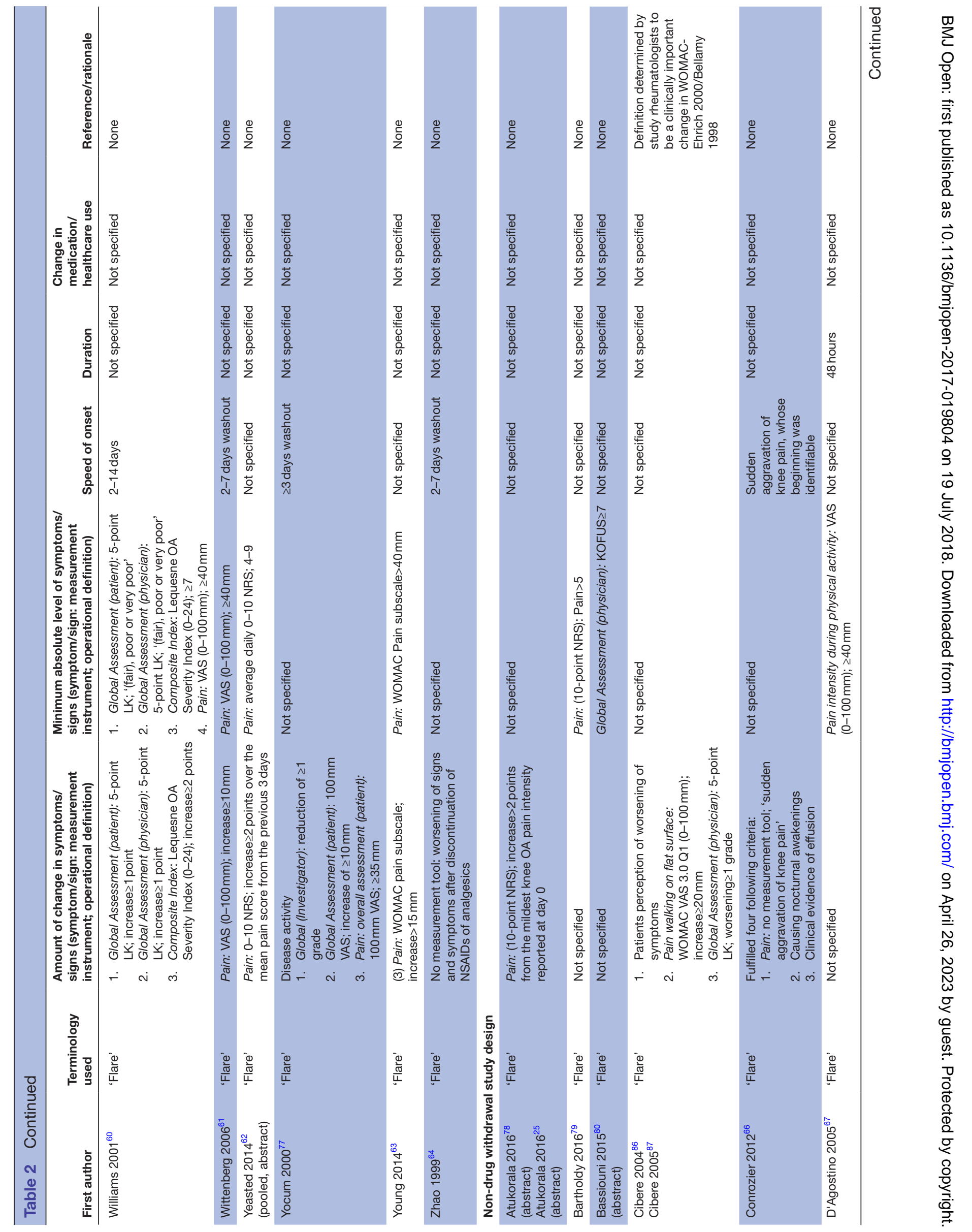




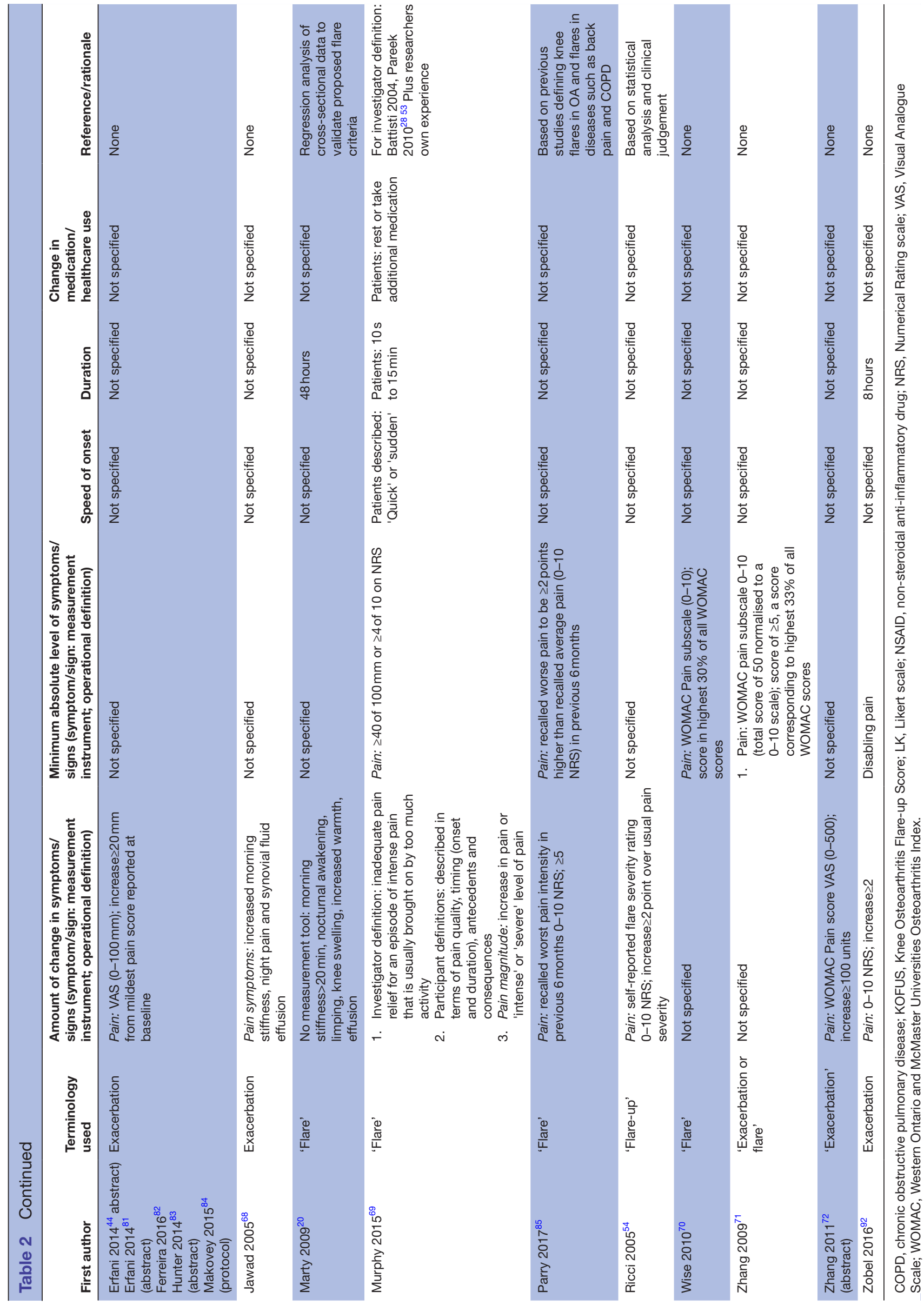

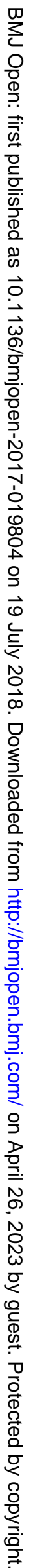


Table 3 Summary of number and type of single-item and multiitem measurement tools used

\section{Single-item scales:}

\begin{tabular}{|c|c|}
\hline Pain on activity: & $\begin{array}{l}\text { WOMAC Q1 } 3.0 \text { VAS 'pain on walking on a flat surface' }(0-100 \mathrm{~mm})(\mathrm{n}=11) \\
\text { Pain on walking VAS }(0-100 \mathrm{~mm})(\mathrm{n}=5) \\
\text { Pain on movement VAS }(0-100 \mathrm{~mm}) \text {; ambulatory pain }(5 \text {-point Likert); pain with physical } \\
\text { activity VAS 11-point scale }(\mathrm{n}=2)\end{array}$ \\
\hline Pain (not further specified): & $\begin{array}{l}\text { Pain VAS }(0-100 \mathrm{~mm})(n=15) \\
\text { Patients assessment of pain score }(0-10) \text {; pain scale }(0-3) \text {; Pain NRS }(0-10)(n=11)\end{array}$ \\
\hline Standing knee pain & Item 5 WOMAC pain scale $(n=1)$ \\
\hline $\begin{array}{l}\text { Global rating } \\
\text { (physician/investigator) }\end{array}$ & $\begin{array}{l}\text { Investigator Assessment of Disease Status }(n=11) \\
\text { Physicians Global Assessment of Arthritis }(n=6) \\
\text { Physician Global Assessment of OA }(n=2) \\
\text { Physician Global Assessment of Disease Status ( } n=2) \text {; Investigator Assessed Pain Grade; } \\
\text { (Physician) Overall Disease Activity (0-100); Physicians Pain Assessment (4-point LK) }(n=3)\end{array}$ \\
\hline Global rating (patient) & $\begin{array}{l}\text { Patients Global Assessment of Arthritis }(n=7) \\
\text { Patient Global Assessment of OA }(n=3) \\
\text { Patient Global Assessment of Disease Status }(n=4)\end{array}$ \\
\hline
\end{tabular}

\section{Multiple-item scales:}

Lequesne OA Severity Index $(n=5)$
WOMAC LK3.1 (0-20) $(n=3)$
WOMAC LK Pain subscale $(0-25)$; WOMAC OA Index Questionnaire $(n=1)$; WOMAC knee pain
score $(0-500)$ [ $n=7]$; KOFUS $(0-14)(n=1)$

KOFUS, Knee Osteoarthritis Flare-up Score; LK, Likert scale; N, number of included studies; OA, osteoarthritis; VAS, Visual Analogue Scale; WOMAC, Western Ontario and McMaster Universities Osteoarthritis Index.

or very poor'. 29304573 The minimum threshold on the Lequesne index (0-10) was either $5^{53}$ or $7 . .^{46} 5160$

\section{Flare definitions in non-withdrawal flare/discontinuation} studies

Terminology used

'Flare' was the term most common used in non-withdrawal design studies $20256667697078-808587(\mathrm{n}=11)$ (table 2). One study used the term 'flare-up', 54 eight used 'exacerbation, $4465687281-84$ (five publications were from the same team) and one referred to both 'exacerbation' and 'flare'. ${ }^{71}$ None referred to 'worsening of symptoms' or did not use any specific label.

\section{Coverage of key components}

Onset/worsening of symptoms and signs beyond normal day-to-day variability: 16 of 22 studies used onset or worsening of symptoms in their definition. ${ }^{25} 4454666869727881-8792$ Two studies did not use pain intensity as part of its definition. ${ }^{2080}$ Three studies included symptoms other than pain in their definition. ${ }^{206668}$ These included nocturnal awakenings, effusion, morning stiffness, night pain, limping and warmth.

The study by Murphy et $a t^{69}$ included an investigator definition of flare and sought to describe patient experience of flares through face-to-face individual interviews. Both investigator and patient definitions included onset/ worsening of symptoms and signs; however, there was no differentiation from day-to-day variability.

Seven studies used a measurement tool to define onset of signs and symptoms (table 3 ). These included the Pain NRS $(0-10),{ }^{25} 54657885$ WOMAC knee pain score VAS
$(0-500),{ }^{72}$ pain walking on a flat surface (WOMAC), ${ }^{86} 87$ Global Assessment of Disease Status (physician) (5-point Likert scale $)^{8687}$ and knee pain VAS not further specified $(0-100) .{ }^{44} 81-84$

Temporal characteristics: only one study set a definition for speed of onset, describing this only as 'sudden' with no further specification. ${ }^{66}$ Patients in the study by Murphy et al used the terms 'quick' and 'sudden' to describe flare onset. ${ }^{69}$ Three studies specified a minimum duration of symptoms ranging from 8 to 48 hours. ${ }^{206567}$ In the study by Murphy et al, patients described duration between $10 \mathrm{~s}$ and 15 min. 69

Change in medication/healthcare usage: no studies used change is medication or healthcare usage as part of their definition. However, in the study by Murphy et al, patients reported either taking rest or using additional medication. 69

Additional domains: two studies defined distribution-based minimum thresholds for flare as the highest $30 \%{ }^{72}$ or highest $33 \%^{73}$ of WOMAC Pain subscale scores among participants in the Longitudinal Examination of Arthritis Pain cohort (total score out of 50 was normalised to a $0-10$ scale).

\section{DISCUSSION}

Flares in OA are recognised in existing clinical guidance $^{94}$ and reviews, ${ }^{95} 96$ but typically merit little more than a passing mention. Our analysis of the definitions has resulted in the findings of common core domains, which will be useful for developing an agreed consensus 
definition for OA flare. From a clinical perspective, a unified definition of a flare could enable clinicians to provide prompt, rationalised and focused treatment. This could also have implications for delivery of self-management strategies involving patients and how episodic management is advocated by clinical guidelines. Our review was motivated by an interest in seeking greater clarity on how these phenomena might be defined by undertaking a broad search strategy, noting that similar efforts have been pursued in other chronic diseases. While we found no current single, agreed definition of OA flare, our review of 69 published studies suggests a number of common domains, which may capture cardinal features. These were: onset/worsening of symptoms and signs, attainment of a minimum symptom threshold during flare, speed of onset/worsening and duration of elevated symptoms/signs. However, we found considerable variation in how these domains have been operationalised for measurement suggesting the need for further conceptual clarification and consensus.

Each potential cardinal feature of OA flare presents different challenges for achieving consensus. The goal of an agreed composite definition is to facilitate both reproducible and comparable research, while enabling more consistent recognition and identification of these phenomena in routine practice. The heterogeneity of OA should also be considered in any definition of a flare-up. Most studies included in our review required an increase in pain over 'usual' or 'baseline' intensity. Although this was measured using a wide range of measurement instruments, several studies selected an increase of 2 or more points on a $0-10$ scale providing a possible starting point for consensus. Yet this possible 'signal' is arguably difficult to interpret without also considering the amount of background 'noise', that is, within-person diurna ${ }^{97}$ and day-to-day variability, ${ }^{98}$ and the absolute level ('minimum threshold') of pain during a flare. There was general concurrence with the minimum threshold that was adopted, for example, $40 \mathrm{~mm}$ on a $0-100 \mathrm{~mm}$ scale and this may indicate the potential level of minimally important clinical difference. In the study by Marty et $a l$, an increase in pain was not independently associated with flare-up after adjusting for other potential features. ${ }^{20}$ However, the studies by Marty $e t a t^{20}$ and Scott-Lennox $e t$ $a \tilde{l}^{56}$ were the only ones that had attempted to derive and/ or validate a prediction model for OA flares. Interestingly, their approaches have not been widely adopted which suggests the complexity of reaching a widely accepted model. Further research on detecting flares over within-person 'normal' variability by collecting frequent repeated measures of pain intensity may be valuable but this approach would not be feasible when identifying flares presenting at the point of care in routine clinical practice. Instead, this may have to rely on the judgement of the patient and/or clinician, the approach used, for example, in defining exacerbations in COPD. ${ }^{1}$ A similar consideration surrounds the speed of onset, which was not well defined by studies in our review. Drug withdrawal design studies specified washout periods between 2 and 15 days, but this is unlikely to be synonymous with speed of onset. The remaining studies used terms such as 'sudden' and 'quick'. In COPD, for instance, a judgement around 'acute onset' or 'sudden onset' appears to be acceptable for clinical recommendations, but we would add that the speed of onset of OA flares ought to be considered also in relation to underlying biologically plausible mechanisms. Indeed, presumed aetiology has been argued as a useful feature in defining acute exacerbations in COPD. ${ }^{99}$ Minimum duration ranged from 8 hours to 5 days in our review; however, this was not widely reported. COPD definitions refer to a 'sustained worsening' of symptoms, ${ }^{2}$ but does not appear to be a feature in other chronic diseases. A minimum duration in OA may help distinguish flares from day-to-day variability. Increase in medication was not found to be a key component in this review despite it being a feature in other chronic diseases such as AS, ${ }^{5} \mathrm{SLE},{ }^{4} 100$ inflammatory bowel disease and ${ }^{101}$ COPD. ${ }^{1}$ Interference with function did not emerge strongly from our review as a cardinal feature of OA flare. In other chronic musculoskeletal conditions, such as back pain, interference with function was not shown to be significantly associated with having a flare-up ${ }^{102}$ and this domain does not feature in the definitions of exacerbations or flares in diseases such as COPD, ${ }^{12}$ asthma, ${ }^{3} \mathrm{AS}^{5}$ or SLE. ${ }^{4}$

Our review has several strengths and some weaknesses that deserve attention. We adopted a broad search strategy, covering a wide range of databases, and featuring bibliography checks, contact with authors, inclusion of conference abstracts, no language restrictions and a minimal threshold (any description or definition of flare) for inclusion. Five studies that were included in a similar review by Cross $e t a l^{103}$ were not included in this study; four did not contain a clear definition of flare-up, including one which gave a definition of knee OA progression and the final paper by Sands $e a^{104}$ was not in our search but the original study was. ${ }^{58}$ We did not, however, search the grey literature and we did not include some potential synonyms as search terms ('attack', 'episode', 'fluctuations'), although these terms appeared often to relate to comorbidities and other phenomena (eg, episodes of care) and would therefore have been a less efficient search strategy than relying on snowball references. Data extraction was performed by only a single reviewer. Nevertheless, we argue that our review provides a reasonably comprehensive summary of how 'flares' in OA have been described and defined in the medical literature. In comparison with the study by Cross $e t a l,{ }^{103}$ our search strategy appeared comprehensive yet efficientreturning 69 included articles compared with 23 . We feel that our review expands on the findings of the review by Cross $e t$ al and adds strength to this important area. The majority of studies describe experimental 'flare design' trials in which flares are induced by drug withdrawal prior to enrolment and randomisation. While intentional or unintentional reduction in usual analgesia may indeed be one trigger for flare, experimentally induced flares 
should not be assumed to represent 'naturally occurring' flares. Flare design trials, for example, are unlikely to capture change in management or healthcare usage that may be a common consequence of OA flares-something that is included in flare definitions in other conditions such as AS, ${ }^{5}$ SLE, ${ }^{400}$ inflammatory bowel disease ${ }^{101}$ and COPD. ${ }^{1}$

A systematic review such as this cannot hope to resolve the need for a common conception and definition of flares in OA. Definitions for exacerbations of disease states are generally reached through a long process of consensus exercises involving key stakeholders, experts and patients in addition to appraisal of relevant literature from studies using multiple methods. ${ }^{6} 8105$ However, we believe that a consensus definition that is reliable, valid and feasible and widely acceptable both clinically and for research purposes should now be sought. The cardinal features described in this review; onset/worsening of symptoms and signs, attainment of a minimum symptom threshold during flare, speed of onset/worsening and duration of elevated symptoms/signs could help start this discussion. Furthermore, observational studies with repeated measures could give an important insight into the nature of these phenomena.

\section{CONCLUSION}

A broad range of ad hoc definitions currently exist in the medical literature. The majority are from drug withdrawal or flare-induced trials rather than 'naturally' occurring flares. The cardinal feature is pain intensity with minimum symptom threshold being another important feature. This review has identified the need to gain consensus on a common definition that can be used for research and clinical application.

Acknowledgements The authors would like to thank Popay et al for allowing to use their guidance on the conduct of narrative synthesis in systematic reviews. The authors would also like to thank Jo Jordan and Opeyemi Babatunde for their advice on conducting a systematic review.

Contributors All authors were involved in conception and design of the study, analysis and interpretation of data, drafting the article, critical revision of the article for important intellectual content, final approval of the article. ELP and MJT extracted and synthesised data. ELP assembled the data. GP takes responsibility for the integrity of the work as a whole from inception to finished article.

Funding ELP is funded by a National Institute for Health Research (NIHR) In Practice Fellowship (IPF-2014-08-03). MJT received funding from a NIHR School for Primary Care Research Launching Fellowship and is currently funded by an Integrated Clinical Academic Programme Clinical Lectureship from the NIHR and Health Education England (HEE) (ICA-CL-2016-02-014). This paper presents independent research funded by the Arthritis Research UK Centre in Primary Care grant (Grant Number 18139).

Disclaimer The views expressed in this paper are those of the author(s) and not necessarily those of the NHS, the NIHR, HEE or the Department of Health.

Competing interests GP received consultancy fees from InFirst and Good Relations.

Patient consent Not required.

Provenance and peer review Not commissioned; externally peer reviewed.

Data sharing statement No additional data are available.
Open access This is an open access article distributed in accordance with the Creative Commons Attribution Non Commercial (CC BY-NC 4.0) license, which permits others to distribute, remix, adapt, build upon this work non-commercially, and license their derivative works on different terms, provided the original work is properly cited, appropriate credit is given, any changes made indicated, and the use is non-commercial. See: http://creativecommons.org/licenses/by-nc/4.0/.

\section{REFERENCES}

1. Global Initiative for Chronic Obstructive Lung Disease. Global Strategy for the diagnosis, management and prevention of COPD: GOLD, 2016.

2. National Institute for Health and Care Excellence (NICE). Chronic obstructive pulmonary disease in over 16s: diagnosis and management (CG101). London: NICE, 2010.

3. Global Initiative for Asthma. Global strategy for asthma management and prevention: GINA, 2015.

4. Ruperto N, Hanrahan LM, Alarcón GS, et al. International consensus for a definition of disease flare in lupus. Lupus 2011;20:453-62.

5. Stone MA, Pomeroy E, Keat A, et al. Assessment of the impact of flares in ankylosing spondylitis disease activity using the Flare Illustration. Rheumatology 2008;47:1213-8.

6. Bingham $\mathrm{CO}$, Alten R, Bartlett SJ, et al. Identifying preliminary domains to detect and measure rheumatoid arthritis flares: Report of the OMERACT 10 RA Flare Workshop. J Rheumatol 2011;38:1751-8.

7. Bykerk VP, Lie E, Bartlett SJ, et al. Establishing a core domain set to measure rheumatoid arthritis flares: report of the OMERACT 11 RA Flare Workshop. J Rheumatol 2014;41:799-809.

8. Bartlett SJ, Hewlett S, Bingham CO, et al. Identifying core domains to assess flare in rheumatoid arthritis: an OMERACT international patient and provider combined Delphi consensus. Ann Rheum Dis 2012;71:1855-60.

9. Taylor WJ, Shewchuk R, Saag KG, et al. Toward a valid definition of gout flare: Results of consensus exercises using delphi methodology and cognitive mapping. Arthritis \& Rheumatism 2009;61:535-43.

10. Schmitt J, Spuls PI, Thomas KS, et al. The Harmonising Outcome Measures for Eczema (HOME) statement to assess clinical signs of atopic eczema in trials. J Allergy Clin Immunol 2014;134:800-7.

11. Holla JFM, van der Leeden M, Knol DL, et al. The association of body-mass index and depressed mood with knee pain and activity limitations in knee osteoarthritis: results from the Amsterdam osteoarthritis cohort. BMC Musculoskelet Disord 2013;14:296.

12. Collins JE, Katz JN, Dervan EE, et al. Trajectories and risk profiles of pain in persons with radiographic, symptomatic knee osteoarthritis: data from the osteoarthritis initiative. Osteoarthritis Cartilage 2014:22:622-30.

13. Leffondré K, Abrahamowicz M, Regeasse A, et al. Statistical measures were proposed for identifying longitudinal patterns of change in quantitative health indicators. $J$ Clin Epidemiol 2004;57:1049-62

14. Emrani PS, Katz JN, Kessler CL, et al. Joint space narrowing and Kellgren-Lawrence progression in knee osteoarthritis: an analytic literature synthesis. Osteoarthritis Cartilage 2008;16:873-82.

15. Bartlett SJ, Ling SM, Mayo NE, et al. Identifying common trajectories of joint space narrowing over two years in knee osteoarthritis. Arthritis Care Res 2011;63:1722-8.

16. Hawker GA, Stewart L, French MR, et al. Understanding the pain experience in hip and knee osteoarthritis - an OARSI/OMERACT initiative. Osteoarthritis Cartilage 2008;16:415-22.

17. Arthritis Research UK. Osteoarthritis: patient information booklet, 2012.

18. Bonnet CS, Walsh DA. Osteoarthritis, angiogenesis and inflammation. Rheumatology 2005;44:7-16.

19. Smith TO, Zou K, Abdullah N, et al. Does flare trial design affect the effect size of non-steroidal anti-inflammatory drugs in symptomatic osteoarthritis? A systematic review and meta-analysis. Ann Rheum Dis 2016;75:1971-8.

20. Marty M, Hilliquin P, Rozenberg $S$, et al. Validation of the KOFUS (Knee Osteoarthritis Flare-Ups Score). Joint Bone Spine 2009;76:268-72.

21. Rutjes AS, Jüni P, Da Costa BR, et al. Viscosupplementation for osteoarthritis of the knee: a systematic review and meta-analysis. Ann Intern Med 2012;157:180-91.

22. Thomas J, Harden A, Newman M. Synthesis: Combining results systematically and appropriately. In: Gough A, Oliver S, Thomas $\mathrm{J}$, eds. An introduction to systematic reviews. London: Sage publications limited, 2013:191-2. 
23. Popay J, Roberts H SA. Guidance on the conduct of narrative synthesis in systematic reviews: a product of the ESRC methods programme. Lancaster: ESRC Method Programme, 2006.

24. Altman R, Hochberg M, Gibofsky A, et al. Efficacy and safety of lowdose SoluMatrix meloxicam in the treatment of osteoarthritis pain: 12-week, phase 3 study. Curr Med Res Opin 2015;31:2331-43.

25. Atukorala I, Pathmeswaran A, Makovey J, et al. Is there a relationship between the Intermittent and Constant Osteoarthritis Pain score (ICOAP) and pain flares in knee osteoarthritis? Osteoarthritis Cartilage 2016;24:S429-30.

26. Baer PA, Thomas LM, Shainhouse Z. Treatment of osteoarthritis of the knee with a topical diclofenac solution: a randomised controlled, 6-week trial [ISRCTN53366886]. BMC Musculoskelet Disord 2005;6:44.

27. Baraf HSB, Gloth FM, Barthel HR, et al. Safety and Efficacy of Topical Diclofenac Sodium Gel for Knee Osteoarthritis in Elderly and Younger Patients. Drugs Aging 2011;28:27-40.

28. Battisti WP, Katz NP, Weaver AL, et al. Pain management in osteoarthritis: A focus on onset of efficacy - a comparison of rofecoxib, celecoxib, acetaminophen, and nabumetone across four clinical trials. The Journal of Pain 2004;5:511-20.

29. Bingham CO, Sebba Al, Rubin BR, et al. Efficacy and safety of etoricoxib $30 \mathrm{mg}$ and celecoxib $200 \mathrm{mg}$ in the treatment of osteoarthritis in two identically designed, randomized, placebocontrolled, non-inferiority studies. Rheumatology 2007;46:496-507.

30. Birbara C, Ruoff G, Sheldon E, et al. Efficacy and safety of rofecoxib $12.5 \mathrm{mg}$ and celecoxib $200 \mathrm{mg}$ in two similarly designed osteoarthritis studies. Curr Med Res Opin 2006;22:199-210.

31. Bocanegra TS, Weaver AL, Tindall EA, et al. Diclofenac/ misoprostol compared with diclofenac in the treatment of osteoarthritis of the knee or hip: a randomized, placebo controlled trial. Arthrotec Osteoarthritis Study Group. J Rheumatol 1998:25:1602-11.

32. Boswell DJ, Ostergaard K, Philipson RS, et al. Evaluation of GW406381 for treatment of osteoarthritis of the knee: two randomized, controlled studies. Medscape J Med 2008;10:259.

33. Brandt KD, Mazzuca SA, Buckwalter KA, et al. Acetaminophen, like conventional NSAIDs, may reduce synovitis in osteoarthritic knees. Rheumatology 2006;45:1389-94.

34. Case JP, Baliunas AJ, Block JA. Lack of efficacy of acetaminophen in treating symptomatic knee osteoarthritis: a randomized, doubleblind, placebo-controlled comparison trial with diclofenac sodium. Arch Intern Med 2003;163:169-78.

35. Ehrich EW, Schnitzer TJ, Mcllwain H, et al. Effect of specific COX 2 inhibition in osteoarthritis of the knee: a 6 week double blind, placebo controlled pilot study of rofecoxib. Rofecoxib Osteoarthritis Pilot Study Group. J Rheumatol 1999;26:2438-47.

36. Essex MN, O'Connell M, Bhadra Brown P. Response to nonsteroidal anti-inflammatory drugs in African Americans with osteoarthritis of the knee. J Int Med Res 2012;40:2251-66.

37. Gibofsky A, Hochberg MC, Jaros MJ, et al. Efficacy and safety of low-dose submicron diclofenac for the treatment of osteoarthritis pain: a 12 week, phase 3 study. Curr Med Res Opin 2014;30:1883-93

38. Gineyts E, et al. Effects of ibuprofen on molecular markers of cartilage and synovium turnover in patients with knee osteoarthritis. Ann Rheum Dis 2004;63:857-61.

39. Goldberg M, Mcllwain H, Poiley J, et al. Controlled-release naproxen in the treatment of osteoarthritis. Current Therapeutic Research-Clinical and Experimental 1988;44:51-60.

40. Gottesdiener K, et al. Results of a randomized, dose-ranging trial of etoricoxib in patients with osteoarthritis. Rheumatology 2002;41:1052-61.

41. Hochberg MC, Fort JG, Svensson O, et al. Fixed-dose combination of enteric-coated naproxen and immediate-release esomeprazole has comparable efficacy to celecoxib for knee osteoarthritis: two randomized trials. Curr Med Res Opin 2011;27:1243-53.

42. Katz N, Sun S, Johnson F, et al. ALO-01 (Morphine Sulfate and Naltrexone Hydrochloride) Extended-Release Capsules in the Treatment of Chronic Pain of Osteoarthritis of the Hip or Knee: Pharmacokinetics, Efficacy, and Safety. The Journal of Pain 2010;11:303-11.

43. Kivitz AJ, Makarowski WS, Fiechtner JJ, et al. A flexible daily dosage regimen of oxaprozin potassium in patients with acute knee pain associated with osteoarthritis. Clin Drug Investig 2001;21:745-53.

44. Erfani T, Zhang Y, Makovey J, et al. Intermittent analgesic use and risk of pain exacerbation in knee osteoarthritis: A web based casecrossover study. Arthritis and Rheumatology 2014;66.

45. Leung AT, Malmstrom K, Gallacher AE, et al. Efficacy and tolerability profile of etoricoxib in patients with osteoarthritis: a randomized, double-blind, placebo and active-comparator controlled 12-week efficacy trial. Curr Med Res Opin 2002:18:49-58.

46. Luyten FP, Geusens P, Malaise M, et al. A prospective randomised multicentre study comparing continuous and intermittent treatment with celecoxib in patients with osteoarthritis of the knee or hip. Ann Rheum Dis 2007;66:99-106.

47. Manicourt D-H, Bevilacqua M, Righini V, et al. Comparative Effect of Nimesulide and?? Ibuprofen on the Urinary Levels of??Collagen Type II C-telopeptide degradation products and on the serum levels of hyaluronan and matrix metalloproteinases- 3 and -13 in??Patients with flare-up of osteoarthritis. Drugs R D 2005;6:261-71.

48. Mazzuca SA, Brandt KD, Lane KA, et al. Knee pain reduces joint space width in conventional standing anteroposterior radiographs of osteoarthritic knees. Arthritis Rheum 2002;46:1223-7.

49. Mcllwain H, Silverfield JC, Cheatum DE, et al. Intra-articular orgotein in osteoarthritis of the knee: a placebo-controlled efficacy, safety, and dosage comparison. Am J Med 1989;87:295-300.

50. Mendelsohn S. Clinical efficacy and tolerability of naproxen in osteoarthritis patients using twice-daily and once-daily regimens. Clinical therapeutics 1991:13:8-15.

51. Moskowitz RW, Sunshine A, Hooper M, et al. An analgesic model for assessment of acute pain response in osteoarthritis of the knee. Osteoarthritis Cartilage 2006;14:1111-8.

52. Pareek A, Chandurkar N, Sharma VD, et al. A randomized, multicentric, comparative evaluation of aceclofenac-paracetamol combination with aceclofenac alone in Indian patients with osteoarthritis flare-up. Expert Opin Pharmacother 2009;10:727-35.

53. Pareek A, Chandurkar N, Ambade R, et al. Efficacy and safety of etodolac-paracetamol fixed dose combination in patients with knee osteoarthritis flare-up: a randomized, double-blind comparative evaluation. Clin J Pain 2010;26:561-6.

54. Ricci JA, Stewart WF, Chee E, et al. Pain exacerbation as a major source of lost productive time in US workers with arthritis. Arthritis \& Rheumatism 2005;53:673-81.

55. Schnitzer TJ, Fricke JR, Gitton X, et al. Lumiracoxib in the treatment of osteoarthritis, rheumatoid arthritis and acute postoperative dental pain: results of three dose-response studies. Curr Med Res Opin 2005;21:151-61.

56. Scott-Lennox JA, McLaughlin-Miley C, Lennox RD, et al. Stratification of flare intensity identifies placebo responders in a treatment efficacy trial of patients with osteoarthritis. Arthritis \& Rheumatism 2001;44:1599-607.

57. Silverfield JC, Kamin M, Wu S-C, et al. Tramadol/acetaminophen combination tablets for the treatment of osteoarthritis flare pain a multicenter, outpatient, randomized, double-blind, placebocontrolled, parallel-group, add-on study. Clin Ther 2002;24:282-97.

58. Strand V, Simon LS, Dougados M, et al. Treatment of osteoarthritis with continuous versus intermittent celecoxib. $J$ Rheumatol 2011;38:2625-34

59. Wiesenhutter CW, Boice JA, Ko A, et al. Evaluation of the comparative efficacy of etoricoxib and ibuprofen for treatment of patients with osteoarthritis: a randomized, double-blind, placebocontrolled trial. Mayo Clin Proc 2005;80:470-9.

60. Williams GW, Hubbard RC, Yu SS, et al. Comparison of once-daily and twice-daily administration of celecoxib for the treatment of osteoarthritis of the knee. Clin Ther 2001;23:213-27.

61. Wittenberg $R$, Schell $E$, Krehan $G$, et al. First-dose analgesic effect of the cyclo-oxygenase-2 selective inhibitor lumiracoxib in osteoarthritis of the knee: a randomized, double-blind, placebocontrolled comparison with celecoxib NCT00267215]. Arthritis Res Ther 2006;8:R35

62. Yeasted R, McPherson J, Schnitzer T. Characterization of osteoarthritis pain variability. Osteoarthritis Cartilage 2014;22:S390-1.

63. Young C, Parenti D, Hochberg M. Lower-dose diclofenac capsules developed using solumatrix fine particle technology result in clinically meaningful improvements in pain in a phase 3 study of patients with osteoarthritis. Osteoarthritis Cartilage 2014;22:S399.

64. Zhao SZ, McMillen JI, Markenson JA, et al. Evaluation of the functional status aspects of health-related quality of life of patients with osteoarthritis treated with celecoxib. Pharmacotherapy 1999;19:1269-78.

65. Zobel I, Erfani T, Bennell K, et al. Relationship of buckling and knee injury to pain exacerbation in knee osteoarthritis: A web-based case-crossover stud. Interact J Med Res 2014;66:S560-1.

66. Conrozier T, Mathieu P, Vignon E, et al. Differences in the osteoarthritic synovial fluid composition and rheology between patients with or without flare: a pilot study. Clin Exp Rheumatol 2012;30:729-34.

67. D'Agostino MA, Conaghan P, Le Bars M, et al. EULAR report on the use of ultrasonography in painful knee osteoarthritis. Part 
1: prevalence of inflammation in osteoarthritis. Ann Rheum Dis 2005;64:1703-9.

68. Jawad ASM. Analgesics and osteoarthritis: are treatment guidelines reflected in clinical practice? Am J Ther 2005;12:98-103.

69. Murphy SL, Lyden AK, Kratz AL, et al. Characterizing pain flares from the perspective of individuals with symptomatic knee osteoarthritis. Arthritis Care Res 2015;67:1103-11.

70. Wise BL, Niu J, Zhang Y, et al. Psychological factors and their relation to osteoarthritis pain. Osteoarthritis Cartilage 2010;18:883-7.

71. Zhang Y, Zhang B, Wise B, et al. Statistical approaches to evaluating the effect of risk factors on the pain of knee osteoarthritis in longitudinal studies. Curr Opin Rheumatol 2009;21:513-9.

72. Zhang Y, Wheaton D N. Recent heavy physical activities trigger knee pain exacerbation in persons with symptomatic knee osteoarthritis. Arthritis \& Rheumatism 2011;63.

73. Day $\mathrm{R}$, Morrison $\mathrm{B}$, Luza A, et al. A randomized trial of the efficacy and tolerability of the COX-2 inhibitor rofecoxib vs ibuprofen in patients with osteoarthritis. Rofecoxib/lbuprofen Comparator Study Group. Arch Intern Med 2000;160:1781-7.

74. Kivitz AJ, Greenwald MW, Cohen SB, et al. Efficacy and safety of rofecoxib $12.5 \mathrm{mg}$ versus nabumetone $1,000 \mathrm{mg}$ in patients with osteoarthritis of the knee: a randomized controlled trial. J Am Geriatr Soc 2004;52:666-74.

75. Bingham CO, Smugar SS, Wang $\mathrm{H}$, et al. Predictors of response to cyclo-oxygenase-2 inhibitors in osteoarthritis: pooled results from two identical trials comparing etoricoxib, celecoxib, and placebo. Pain Medicine 2011;12:352-61.

76. Essex MN, Behar R, O'Connell MA, et al. Efficacy and tolerability of celecoxib and naproxen vs placebo in hispanic patients with knee osteoarthritis. Osteoarthritis Cartilage 2013;21:S252.

77. Yocum D, Fleischmann R, Dalgin P, et al. Safety and efficacy of meloxicam in the treatment of osteoarthritis: a 12-week, doubleblind, multiple-dose, placebo-controlled trial. The Meloxicam Osteoarthritis Investigators. Arch Intern Med 2000;160:2947-54.

78. Atukorala I, Pathmeswaran A, Chang T, et al. SAT0452 do traditional risk factors for knee osteoarthritis predict pain flares in knee osteoarthritis?: Table 1. Ann Rheum Dis 2016;75:835.2-835.

79. Bartholdy C, Klokker L, Bandak E, et al. A standardized "rescue" exercise program for symptomatic flare-up of knee osteoarthritis: description and safety considerations. Journal of Orthopaedic \& Sports Physical Therapy 2016;46:942-6.

80. Bassiouni H. Detection of changes in the serum and synovial fluid levels of resistin during flare ups and remissions in primary knee osteoarthritis. Arthritis and Rheumatology 2015;67.

81. Erfani T, Makovey J, Bennell K, et al. Psychosocial factors and pain exacerbation in knee osteoarthritis: a web based case-crossover study. Intern Med J 2014;44:16.

82. Ferreira ML, Zhang $Y$, Metcalf $B$, et al. The influence of weather on the risk of pain exacerbation in patients with knee osteoarthritis - a case-crossover study. Osteoarthritis Cartilage 2016;24:2042-7.

83. Hunter DJ, Bennell K, Makovey J, et al. Psychosocial factors and pain exacerbation in knee osteoarthritis: a web based casecrossover study. Osteoarthritis Cartilage 2014;22:S21-S22.

84. Makovey J, Metcalf B, Zhang Y, et al. Web-based study of risk factors for pain exacerbation in osteoarthritis of the knee (SPARKWeb): design and rationale. JMIR Res Protoc 2015;4:e80.

85. Parry E, Ogollah R, Peat G. Significant pain variability in persons with, or at high risk of, knee osteoarthritis: preliminary investigation based on secondary analysis of cohort data. BMC Musculoskelet Disord 2017:18:80.

86. Cibere J, Kopec JA, Thorne A, et al. Randomized, double-blind, placebo-controlled glucosamine discontinuation trial in knee osteoarthritis. Arthritis \& Rheumatism 2004;51:738-45.
87. Cibere J, Thorne A, Kopec JA, et al. Glucosamine sulfate and cartilage type II collagen degradation in patients with knee osteoarthritis: randomized discontinuation trial results employing biomarkers. J Rheumatol 2005;32:896-902.

88. Roth SH, Shainhouse JZ. Efficacy and safety of a topical diclofenac solution (pennsaid) in the treatment of primary osteoarthritis of the knee: a randomized, double-blind, vehicle-controlled clinical trial. Arch Intern Med 2004;164:2017-23.

89. Simon LS, Grierson LM, Naseer Z, et al. Efficacy and safety of topical diclofenac containing dimethyl sulfoxide (DMSO) compared with those of topical placebo, DMSO vehicle and oral diclofenac for knee osteoarthritis. Pain 2009;143:238-45.

90. Weaver A, Rubin B, Caldwell J, et al. Comparison of the efficacy and safety of oxaprozin and nabumetone in the treatment of patients with osteoarthritis of the knee. Clin Ther 1995;17:735-45.

91. Rother M, Lavins BJ, Kneer W, et al. Efficacy and safety of epicutaneous ketoprofen in Transfersome (IDEA-033) versus oral celecoxib and placebo in osteoarthritis of the knee: multicentre randomised controlled trial. Ann Rheum Dis 2007;66:1178-83.

92. Zobel I, Erfani T, Bennell KL, et al. Relationship of buckling and knee injury to pain exacerbation in knee osteoarthritis: a web-based case-crossover study. Interact J Med Res 2016;5:e17.

93. Woolacott NF, Corbett MS, Rice SJC. The use and reporting of WOMAC in the assessment of the benefit of physical therapies for the pain of osteoarthritis of the knee: findings from a systematic review of clinical trials. Rheumatology 2012;51:1440-6.

94. National Institute for Health and Care Excellence (NICE). Osteoarthritis: care and management (CG177). London: NICE, 2014.

95. Buttgereit F, Burmester G-R, Bijlsma JWJ. Non-surgical management of knee osteoarthritis: where are we now and where do we need to go? RMD Open 2015;1:e000027.

96. Porcheret M, Healey E, Dziedzic K, et al. Ostoearthritis: a modern approach to diagnosis and management. Arthritis Research UK 2011;6.

97. Bellamy N, Sothern RB, Campbell J. Rhythmic variations in pain perception in osteoarthritis of the knee. $J$ Rheumatol 1990;17:364-72.

98. Allen KD, Coffman CJ, Golightly YM, et al. Daily pain variations among patients with hand, hip, and knee osteoarthritis. Osteoarthritis Cartilage 2009;17:1275-82.

99. Makris D, Bouros D. COPD exacerbation: lost in translation. BMC Pulm Med 2009;9:6.

100. Fitzgerald JD, Grossman JM. Validity and reliability of retrospective assessment of disease activity and flare in observational cohorts of lupus patients. Lupus 1999;8:638-44.

101. Lewis JD, Aberra FN, Lichtenstein GR, et al. Seasonal variation in flares of inflammatory bowel disease. Gastroenterology 2004;126:665-73.

102. Suri P, Saunders KW, Von Korff M. Prevalence and characteristics of flare-ups of chronic nonspecific back pain in primary care. Clin $\mathrm{J}$ Pain 2012;28:573-80.

103. Cross $M$, Dubouis L, Mangin M, et al. Defining flare in osteoarthritis of the hip and knee: a systematic literature review - omeract virtual special interest group. J Rheumatol 2017:44:1920-7.

104. Sands GH, Brown PB, Essex MN. The efficacy of continuous versus intermittent celecoxib treatment in osteoarthritis patients with Body Mass Index $\geq 30$ and $<30 \mathrm{~kg} / \mathrm{m}(2$.). Open Rheumatol J 2013;7:32-7.

105. Berthelot J-M, De Bandt M, Morel J, et al. A tool to identify recent or present rheumatoid arthritis flare from both patient and physician perspectives: The 'FLARE' instrument. Ann Rheum Dis 2012;71:1110-6. 